\title{
Evolution of renal function after partial and full mechanical support for chronic heart failure
}

\author{
Steven Jacobs ${ }^{1}$, Walter Droogne ${ }^{2}$, Valerie Waelbers' ${ }^{1}$ Klaartje Van den Bossche ${ }^{1}$, Hilde Bollen ${ }^{1}$, \\ Jef Geens ${ }^{1}$, Filip Rega ${ }^{1}$, Daniel Burkhoff ${ }^{3,4}$, Bart Meyns ${ }^{1}$ \\ ${ }^{1}$ Cardiac Surgery, Catholic University Leuven, Leuven - Belgium \\ ${ }^{2}$ Cardiology, Catholic University Leuven, Leuven - Belgium \\ ${ }^{3}$ Columbia University, New York, New York - USA \\ ${ }^{4}$ CircuLite, Inc., Saddle Brook, New Jersey - USA
}

Purpose: Recently a minimal invasive, partial support continuous flow left ventricular assist device (LVAD) became available for treatment of chronic heart failure. The aim of this study was to analyze whether partial support is capable of improving kidney function in end-stage heart failure.

Methods: We performed a single-center retrospective analysis of patients how received a full $(n=43)$ or partial support LVAD $(n=18)$ between 2007 and 2013. Patients on dialysis or in INTERMACS class I were excluded. Renal function was assessed until 3 months after the implantation. A calculated GFR less than $60 \mathrm{~m} / \mathrm{min}$ was considered to be renal failure.

Results: Creatinine level after LVAD implant decreased $23 \%$ in patients on full support $(1.3 \pm 0.4 \mathrm{mg} /$ dl vs. $1.0 \pm 0.3 \mathrm{mg} / \mathrm{dl} ; p<0.001)$ and $24 \%$ in patients on partial support $(1.6 \pm 0.6 \mathrm{mg} / \mathrm{dl}$ vs. $1.2 \pm 0.4$ $\mathrm{mg} / \mathrm{dl} ; p=0.17$ ) within 3 months. In each group patients with a preoperative GFR less than $60 \mathrm{ml} / \mathrm{min}$ were selected. In this subgroup there was a $35 \%$ decrease in creatinine levels for patients on full support $(1.7 \pm 0.4 \mathrm{mg} / \mathrm{dl}$ vs. $1.1 \pm 0.5 \mathrm{mg} / \mathrm{dl} ; p<0.01)$ and a $32 \%$ decrease in patients on partial support $(2 \pm 0.4 \mathrm{mg} / \mathrm{dl}$ vs. $1.4 \pm 0.3 \mathrm{mg} / \mathrm{dl} ; p<0.05)$ at 3 months.

Conclusions: We observed a significant improvement in renal function in patients supported by full or partial support devices, even if the preoperative renal function was severly impaired. The use of diuretics decreased in both groups. In chronic heart failure patients with impaired renal function, partial support is sufficient to improve renal function significantly.

Keywords: LVAD, Partial support, Renal function

Accepted: March 19, 2014

\section{INTRODUCTION}

Heart failure is a major public health problem affecting millions of people worldwide (1). Over the last few decades there has been an increase in the prevalence of heart failure (2-4). Heart failure is associated with an increased mortality, with 5-year survival rates of $41 \%$ to $60 \%(5,6)$. Patients with end-stage heart failure have multiple comorbidities including end-organ failure and cardiac cachexia (7-9). Impairment in renal function in particular is shown to be an independent risk factor for mortality and re-hospitalization in heart failure patients and deterioration of renal function is often the driver to augment medical therapy (10).

Over the last decade left ventricular assist devices (LVADs) have been increasingly used in end-stage heart failure (11). Both pulsatile and non-pulsatile LVADs have been shown to increase survival in patients with end-stage heart failure $(12,13)$. Despite early concerns regarding non-pulsatile flow, non-pulsatile LVADs have shown to improve end-organ function in patients with advanced 
heart failure (14-17). Moreover, renal function improvement after LVAD implantation is associated with improved survival (16).

Recently a new, less invasive left ventricular assist device became available for the treatment of chronic heart failure (18). This miniaturized assist device has an inflow cannula in the left atrium and outflow to the right subclavian artery. In this configuration, the pump delivers only partial circulatory support ( $\pm 3 \mathrm{l} / \mathrm{min}$ ). This partial support device is advocated in patients with less severe cardiac disease, who are still ambulatory. It is of interest to know if renal function restores to the same level with partial support as compared to full support. We sought to analyze if partial support is equally efficient in restoring renal function in chronic heart failure patients.

\section{PATIENTS AND METHODS}

\section{Patients}

A consecutive series of patients undergoing LVAD implantation between June 2007 and March 2013 for chronic heart failure was retrospectively analyzed. Hospital files were retrieved of patients undergoing at least 90 days of support. Files with incomplete data were excluded. To avoid confusion with changes in renal function after acute heart failure and shock, we excluded patients dependent on renal dialysis before VAD implantation and patients in INTERMACS (Interagency Registry for Mechanically Assisted Circulatory Support) class 1. In doing so we selected 61 patients (43 full support; 18 partial support) out of 101 patients undergoing LVAD implantation.

Patient demographics undergoing either partial support or full support are shown in Table I. Preoperative hemodynamic and laboratory parameters are shown in Table II. There is a marked difference in INTERMACS class between the two patient populations. A significant proportion of the patients who were implanted with a full support device needed inotropes preoperatively whereas the use of inotropes in the partial support group was non-existent. This is also reflected by their higher INTERMACS class. However, the overall demographic and hemodynamic profiles of both patient groups are similar, keeping in mind that some full support patients needed inotropic support to maintain their hemodynamics.
TABLE I - PRE-IMPLANT PATIENT DEMOGRAPHICS

\begin{tabular}{lccc}
\hline & $\begin{array}{c}\text { Full support } \\
(\mathbf{n}=\mathbf{4 3})\end{array}$ & $\begin{array}{c}\text { Partial support } \\
(\mathbf{n}=\mathbf{1 8})\end{array}$ & $\boldsymbol{P}$ value \\
\hline Age (years) & $50.1 \pm 14$ & $55.3 \pm 16$ & 0.23 \\
Gender & $35 / 8$ & $17 / 1$ & 0.06 \\
(Male /Female) & & & \\
BSA (m $\left.{ }^{2}\right)$ & $1.9 \pm 0.2$ & $1.8 \pm 0.2$ & 0.05 \\
BMI (kg/m²) & $24.7 \pm 3.4$ & $23.2 \pm 4.1$ & 0.17 \\
ICM/DCM & $20 / 23$ & $11 / 7$ & 0.15 \\
INTERMACS class & & & \\
II & 17 & 1 & \\
III & 14 & 1 & \\
IV & 10 & 10 & \\
IV-VII & 2 & 6 & \\
\hline
\end{tabular}

Data are expressed as mean and standard deviation. $\mathrm{BSA}=$ body surface area; $\mathrm{BMI}=$ body mass index; ICM = ischemic cardiomyopathy; $\mathrm{DCM}=$ dilated cardiomyopathy.

TABLE II - PRE-IMPLANT PATIENT HEMODYNAMIC AND LABORATORY DATA

\begin{tabular}{|c|c|c|c|}
\hline & $\begin{array}{l}\text { Full support } \\
\qquad(n=43)\end{array}$ & $\begin{array}{l}\text { Partial support } \\
\qquad(n=18)\end{array}$ & $P$ value \\
\hline $\begin{array}{l}\text { Wedge pressure } \\
(\mathrm{mmHg})\end{array}$ & $28.1 \pm 7.8$ & $30.4 \pm 8.6$ & 0.36 \\
\hline CVP $(\mathrm{mmHg})$ & $15.8 \pm 6.8$ & $14.3 \pm 4.9$ & 0.37 \\
\hline PAP mean $(\mathrm{mmHg})$ & $37.4 \pm 9.2$ & $42,8 \pm 11.2$ & 0.1 \\
\hline $\begin{array}{l}\text { Mean arterial } \\
\text { pressure }(\mathrm{mmHg})\end{array}$ & $73.3 \pm 9.2$ & $73.9 \pm 7.5$ & 0.8 \\
\hline $\begin{array}{l}\text { Cardiac index } \\
\left(1 / \text { min per } \mathrm{m}^{2}\right)\end{array}$ & $1.8 \pm 0.5$ & $1.9 \pm 0.4$ & 0.34 \\
\hline $\begin{array}{l}\text { Cardiac power } \\
\text { index }\left(\mathrm{W} / \mathrm{m}^{2}\right)\end{array}$ & $0.3 \pm 0.1$ & $0.3 \pm 0.1$ & 0.39 \\
\hline EF (\%) & $16.7 \pm 5$ & $19.4 \pm 5.8$ & 0.11 \\
\hline $\begin{array}{l}\text { Inotropic support } \\
\text { (Yes/No) }\end{array}$ & $24 / 19$ & $0 / 18$ & $<0.00001$ \\
\hline NT-proBNP (ng/l) & $9362 \pm 7410$ & $8326 \pm 10580$ & 0.71 \\
\hline CRP (mg/l) & $39.7 \pm 48.9$ & $10.3 \pm 13.9$ & $<0.001$ \\
\hline Creatinine (mg/dl) & $1.3 \pm 0.4$ & $1.6 \pm 0.6$ & $<0.05$ \\
\hline GFR (ml/min) & $68 \pm 23$ & $54 \pm 26$ & 0.1 \\
\hline BUN (mg/dl) & $60 \pm 23$ & $85 \pm 41$ & $<0.05$ \\
\hline
\end{tabular}

Data are expressed as mean and standard deviation. CVP = central venous pressure; PAP = pulmonary artery pressure; EF = ejection fraction; CRP = $\mathrm{C}$-reactive protein; GFR = glomerular filtration rate; $\mathrm{BUN}=$ Blood urea nitrogen. 


\section{Partial support}

The Synergy micropump ${ }^{\odot}$ (CircuLite, Inc., Saddlebrooke, $\mathrm{NJ}$, USA) is a miniaturized L VAD. It connects to the heart through the left atrium and has its outflow graft connected to the right subclavian artery. The assist device is implanted off-pump through a small right thoracotomy. The pump itself is placed subcutaneously in a right-sided pacemaker pocket. The pump is able to provide pump flows up to four liters per minute and is used mostly in a partial support configuration (2.5-3 l/min) (18).

\section{Renal function}

Renal function is described by plasma creatinine levels and the glomerular filtration rate (GFR), calculated by the MDRD (Modification of Diet in Renal Disease) formula (19).

GFR $=186 \times$ Serum Creatinine ${ }^{-1.154} \times$ Age $^{-0.203} \times[0.742$ if female]

In line with the consensus of the KDIGO (Kidney Disease: Improving Global Outcomes) working group, a glomerular filtration rate (GFR) less than $60 \mathrm{ml} / \mathrm{min}$ was considered to be renal failure (20).

\section{Data and statistical analysis}

Data were collected retrospectively from the patients' hospital charts. Renal function was assessed at days 1, 3, 5, 10, and 14 after implantation and then monthly until 3 months after implantation. Continuous variables are presented by their means and standard deviation. Comparisons are made with unpaired Student $t$-test between groups and with repeated measures ANOVA (with a Greenhouse-Geisser correction and post hoc tests using the Bonferroni correction) between different time points in each group.

$P$ values less than 0.05 are considered significant.

\section{RESULTS}

\section{Renal function before VAD implantation}

Renal function was significantly impaired in this population of chronic heart failure patients, with a mean GFR of $64 \pm 24 \mathrm{ml} / \mathrm{min}$. Despite the fact that they were less

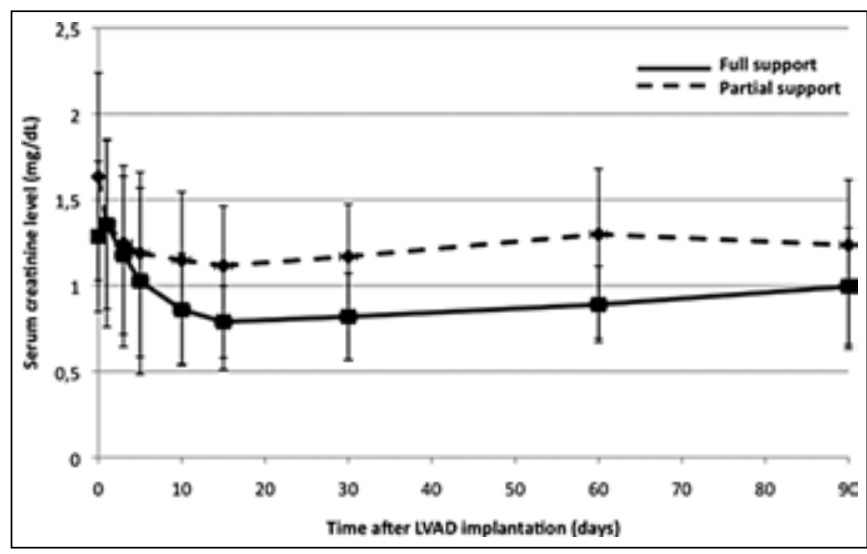

Fig. 1 - Evolution of plasma creatinine levels after LVAD implantation for patients receiving full (solid line; $n=43$ ) versus partial (dashed line; $n=18$ ) support.

symptomatic, patients who were to receive partial support had higher plasma levels of creatinine and urea than patients receiving full support. Their GFR was also slightly lower ( $56 \pm 26 \mathrm{ml} / \mathrm{min}$ vs. $68 \pm 23 \mathrm{ml} / \mathrm{min} ; \mathrm{p}=0.09$ ).

The average NT-proBNP ( $\mathrm{N}$-terminal pro-brain natriuretic peptide) in this study population was markedly elevated $(9017 \pm 8509 \mathrm{ng} / \mathrm{l})$ and NT-proBNP levels were equally elevated in both subgroups (full support: $9362 \pm 7410 \mathrm{ng} / \mathrm{l}$ vs. partial support: $8326 \pm 10579 \mathrm{ng} / \mathrm{l} ; \mathrm{p}=0.71$ ).

\section{Renal function after full or partial support}

Preoperative creatinine and BUN levels were significantly higher in patients selected for partial support implantation (Tab. II). Creatinine level after LVAD implantation decreased $39 \%$ in patients on full support $(1.3 \pm 0.4 \mathrm{mg} / \mathrm{dl}$ vs. $0.8 \pm$ $0.2 \mathrm{mg} / \mathrm{dl} ; \mathrm{p}<0.00001)$ and $32 \%$ in patients on partial support $(1.6 \pm 0.6 \mathrm{mg} / \mathrm{dl}$ vs. $1.1 \pm 0.3 \mathrm{mg} / \mathrm{dl} ; \mathrm{p}<0.001)$ within the first two weeks. At three months after implantation creatinine levels had decreased $23 \%$ in patients on full support $(1.3 \pm 0.4 \mathrm{mg} / \mathrm{dl}$ vs. $1.0 \pm 0.3 \mathrm{mg} / \mathrm{dl} ; \mathrm{p}<0.001)$ and $24 \%$ in patients on partial support $(1.6 \pm 0.6 \mathrm{mg} / \mathrm{dl}$ vs. 1.2 $\pm 0.4 \mathrm{mg} / \mathrm{dl} ; \mathrm{p}=0.17$ ) (Fig. 1). BUN level showed a similar trend with a $41 \%$ decrease in BUN level at 3 months in full support patients $(60.2 \pm 23.5 \mathrm{mg} / \mathrm{dl}$ vs. $35.7 \pm 15 \mathrm{mg} / \mathrm{dl}$; $\mathrm{p}<0.00001)$ and a $34 \%$ decrease in partial support patients $(84.7 \pm 41 \mathrm{mg} / \mathrm{dl}$ vs. $55.8 \pm 29.1 \mathrm{mg} / \mathrm{dl} ; p<0.05)$. In accordance with the changes in creatinine and BUN levels, the GFR in these patients rose significantly in the first two weeks and remained significantly higher at three months (Fig. 2). 


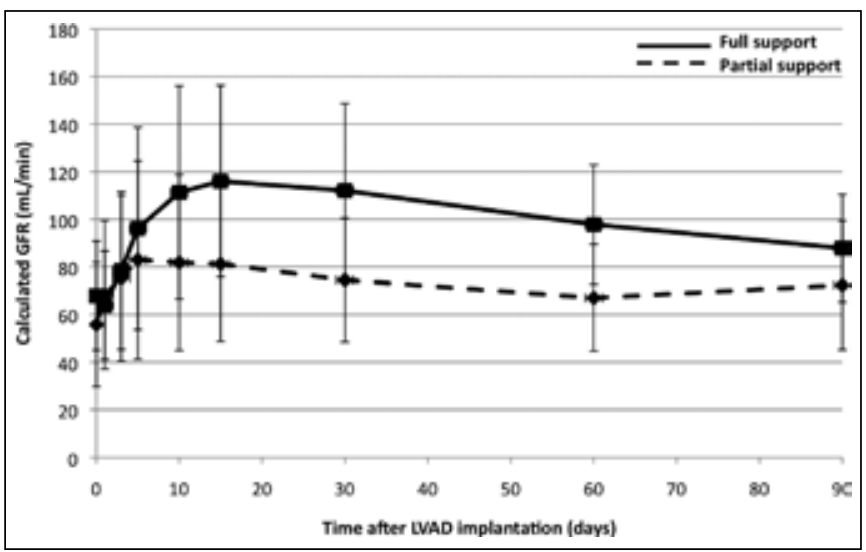

Fig. 2 - Evolution of glomerular filtration rate (GFR) after LVAD implantation for patients receiving full (solid line; $n=43$ ) versus partial (dashed line; $n=18$ ) support.

\section{Use of bumetadine after full or partial support}

Before LVAD implantation $79 \%$ of patients on full support and $100 \%$ of patients on partial support needed treatment with bumetadine (Burinex ${ }^{\circledR}$; LEO Pharma, Ballerup, Denmark). After 3 months of support the percentage of patients needing bumetadine and the daily dose was diminished in both groups (Tab. III). Only three patients on full support were treated with furosemide before implantation of the device and after three months of LVAD support only two were still on this drug.

\section{Renal function after full or partial support in patients with preoperative renal function impairment}

We selected patients with a preoperative impaired renal function (GFR less than $60 \mathrm{ml} / \mathrm{min}$; see methods) and compared their postoperative renal function according to the type of support they received (full, $n=17$ vs. partial support, $n=11$ ). Preoperative creatinine and BUN levels were significantly higher in patients about to receive partial support as compared with patients selected for full support $(2 \pm 0.4 \mathrm{mg} / \mathrm{dl}$ vs. $1.7 \pm 0.4 \mathrm{mg} / \mathrm{dl} ; \mathrm{p}<0.05$ and $108.5 \pm$ $33.5 \mathrm{mg} / \mathrm{dl}$ vs. $74.4 \pm 24.4 \mathrm{mg} / \mathrm{dl} ; \mathrm{p}<0.01)$. The plasma creatinine levels declined significantly over the first 2 weeks in both groups. Creatinine levels of patients on full support dropped $47 \%(1.7 \pm 0.4 \mathrm{mg} / \mathrm{dl}$ vs. $0.9 \pm 0.25 \mathrm{mg} / \mathrm{dl}$; $p<0.0001)$ and $35 \%$ in patients on partial support $(2 \pm 0.4$ $\mathrm{mg} / \mathrm{dl}$ vs. $1.3 \pm 0.3 \mathrm{mg} / \mathrm{dl} ; \mathrm{p}<0.001)$. At three months there
TABLE III - USE OF BUMETANIDE PRE-LVAD AND AFTER 3 MONTHS OF SUPPORT

\begin{tabular}{lccc}
\hline & Pre-LVAD & $\begin{array}{c}\text { 3 months } \\
\text { of support }\end{array}$ & P - value \\
\hline $\begin{array}{l}\text { Bumetanide use (\% of patients) } \\
\text { Partial support } \\
(\mathrm{n}=18)\end{array}$ & $18(100)$ & 0.08 \\
$\begin{array}{l}\text { Full support } \\
(\mathrm{n}=43)\end{array}$ & $34(79)$ & $16(37)$ & $<0.0001$ \\
$\begin{array}{l}\text { Bumetanide dose }(\mathrm{mg} / \text { day) } \\
\text { Partial support }\end{array}$ & $3.6 \pm 2.3$ & $2.0 \pm 1.9$ & $<0.05$ \\
Full support & $4.7 \pm 2.1$ & $1.3 \pm 1.0$ & $<0.01$ \\
\hline
\end{tabular}

Data are expressed as mean and standard deviation. Bumetanide $=$ Burinex $^{\oplus}$; Leo Pharma, Ballerup, Denmark.

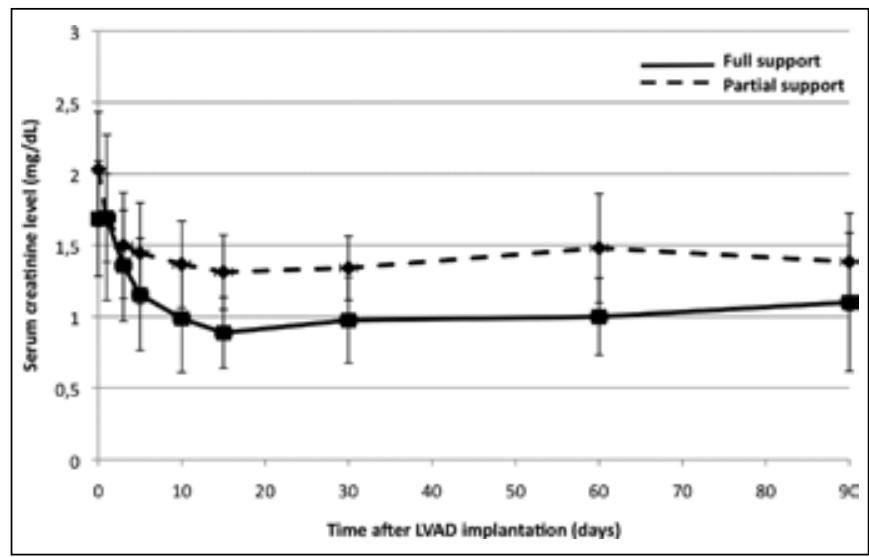

Fig. 3 - Evolution of plasma creatinine levels after LVAD implantation for patients with preoperative impaired renal function receiving full (solid line; $n=17$ ) versus partial (dashed line; $n=11$ ) support.

still was a $35 \%$ decrease in creatinine levels for patients on full support $(1.7 \pm 0.4 \mathrm{mg} / \mathrm{dl}$ vs. $1.1 \pm 0.5 \mathrm{mg} / \mathrm{dl} ; \mathrm{p}<0.01)$ and a $32 \%$ decrease in patients on partial support $(2 \pm$ $0.4 \mathrm{mg} / \mathrm{dl}$ vs. $1.4 \pm 0.3 \mathrm{mg} / \mathrm{dl} ; \mathrm{p}<0.05$ ) (Fig. 3). The BUN level in both groups showed similar pattern with a $47 \%$ decrease after three months in the full support group $(74.4 \pm$ $24.4 \mathrm{mg} / \mathrm{dl}$ vs. $39.6 \pm 17.7 \mathrm{mg} / \mathrm{dl} ; \mathrm{p}<0.001)$ and a $37 \%$ decrease in the partial support group $(108.5 \pm 33.5 \mathrm{mg} / \mathrm{dl}$ vs. $68.7 \pm 30 \mathrm{mg} / \mathrm{dl} ; \mathrm{p}<0.05)$.

The GFR rose significantly within two weeks to more than $60 \mathrm{ml} / \mathrm{min}$ in both groups. After three months GFR had 


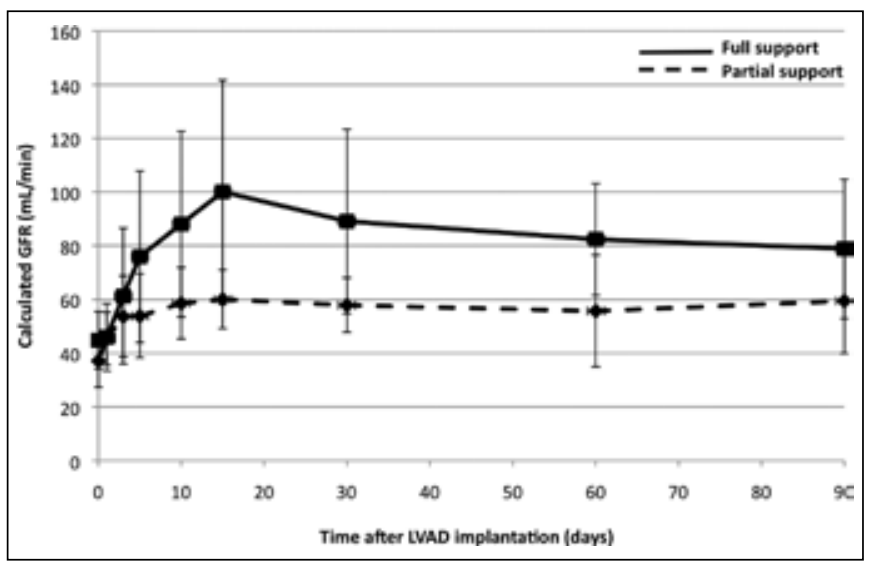

Fig. 4 - Evolution of glomerular filtration rate (GFR) after LVAD implantation for patients with preoperative impaired renal function receiving full (solid line; $n=17$ ) versus partial (dashed line; $n=11$ ) support.

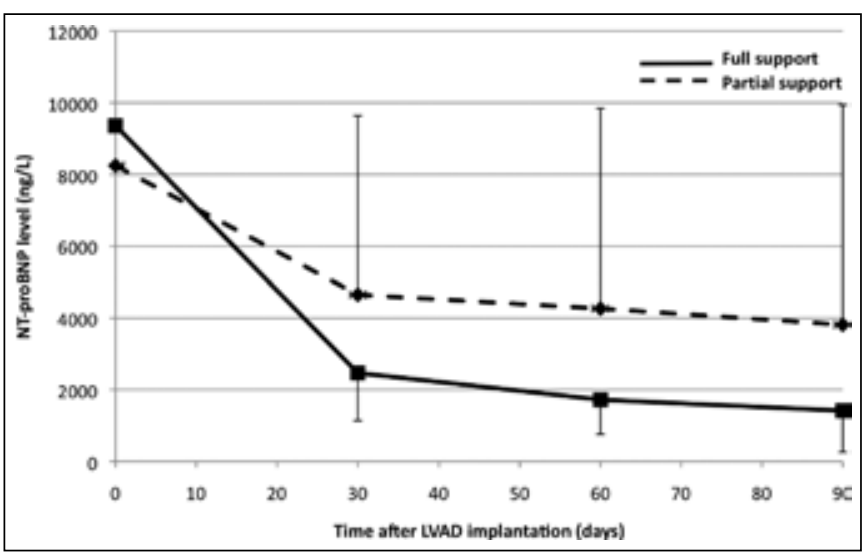

Fig. 5 - Evolution of plasma NT-proBNP levels after LVAD implantation for patients receiving full (solid line; $n=43$ ) versus partial (dashed line; $n=18$ ) support.

increased $75 \%$ in patients on full support $(44.8 \pm 10.7 \mathrm{ml} /$ min vs. $78.9 \pm 26 \mathrm{ml} / \mathrm{min} ; \mathrm{p}<0.001)$ and $60 \%$ in patients on partial support $(37.2 \pm 9.8 \mathrm{ml} / \mathrm{min}$ vs. $59.5 \pm 19.5 \mathrm{ml} / \mathrm{min}$; $\mathrm{p}<0.05$ ) (Fig. 4).

\section{Evolution of natriuretic peptides after partial and full support}

NT-proBNP levels measured after LVAD implantation showed a rapid decline in both groups (Fig. 5). In patients receiving full support the decrease was more pronounced as compared to patients receiving partial support. After three months NT-proBNP levels dropped to $1418 \pm 1161 \mathrm{ng} / \mathrm{l}$ in patients on full support $(p<0.0001)$ and to $3816 \pm 6124 \mathrm{ng} / \mathrm{l}$ in patients on partial support $(p=0.13)$.

\section{DISCUSSION}

Continuous flow left ventricular assist devices have become an important treatment option in end-stage heart failure. They have shown to improve survival rates compared to medical treatment (21). Previous publications have shown improvement in kidney function after LVAD implantation (22). In this paper we analyzed renal function after implantation of full and partial support devices. We observed that in both groups the renal function improved significantly after LVAD implantation, even in those patients who hadan impaired renal function preoperatively (GFR less than $60 \mathrm{ml} / \mathrm{min}$ ). Patients prone to receive partial support had a higher INTERMACS class, were less dependent on inotropes but had a similar hemodynamic prophile and similar plasma levels of natriuretic peptides. Amazingly, their renal function was worse before LVAD implantation. Previous reports indicated that the hemodynamic state is well restored with partial support and that this remains the case over time (23). Our observations show that the renal function is also restored in patients who receive a partial support device. This confirms the expectation that chronic heart failure patients can be treated with less invasive support devices. Restoration of renal function is an important effect as the deterioration of renal function is life-threatening and difficult to mediate with medical therapy in the frail chronic heart failure patient.

Impairment of renal function in chronic heart failure has been classified as type 2 cardiorenal syndrome (24). The underlying pathophysiology of renal impairment in chronic heart failure is probably a combination of hemodynamic factors such as transrenal perfusion pressure and systemic neurohormonal factors (25). Transrenal perfusion pressure (mean arterial pressure minus central venous pressure) in chronic heart failure is affected by a lowered cardiac output and venous congestion. The ESCAPE (Evaluation Study of Congestive Heart Failure and Pulmonary Catheterization Effectiveness) trial demonstrated no link between hemodynamic variables measured by pulmonary artery catheter and serum creatinine in 194 patients (26). As there seemed to be a link with right atrial pressure, the idea came about that venous congestion is a significant contributor to renal failure. In this series, there was no correlation between the 
preoperative central venous pressure and the renal function. Assist devices improve significantly the transrenal perfusion pressure by both increasing arterial pressure in the renal artery and lowering central venous pressure. The lesser invasive partial support device, with an inflow cannula positioned in the left atrium, still requires a significant contribution of the native left ventricle and therefore sufficient preload. One might expect that venous congestion is still present to some degree. Our observation confirms that the hemodynamic improvements obtained by partial support are also effective to restore renal function.

The neurohormonal abnormalities described in cardiorenal syndrome type 2 are an excessive production of vasoconstrictive mediators (epinephrine, angiotensine, endothelin) and release of vasodilatory factors (natriuretic peptides, nitric oxide) (24). The evolution of natriuretic peptides showed a similar trend in both types of ventricular support. The immediate decrease of plasma levels of natriuretic peptides indicates that myocardial congestion was halted. The stoppage of this neurohormonal pathway by itself can be a significant contributor to the improved in renal function.

The volume load of patients with assist devices is clinically difficult to assess. Most patients are on aggressive regimens of diuretics before the VAD implantation and are weaned off this medication afterwards. Our data show that also patients on partial support have a significant reduction in the daily doses of diuretics. We have insufficient data to know if it is beneficial for the long-term renal function to maintain patients on LVADs on optimized vasodilator therapy. It is intuitive to assume that vasodilator therapy is beneficial in patients on partial support given the partial contribution of the failing native heart.

\section{Limitations}

Our analysis was retrospective and the tendency to receive full or partial support was determined by the clinical condition of the patient. In order to avoid the confounding effects of shock in the full support group we excluded all patients in INTERMACS class 1. However, the patient profile is significantly different and one must be careful with the direct comparison between data from the two treatment groups.

\section{CONCLUSIONS}

In chronic heart failure patients with impaired renal function, partial support is sufficient to significantly improve renal function.

\section{Disclosures}

Approval of the Institutional Ethics Committee was obtained (Study number: S52659)

Financial Support: None.

Conflict of Interest: Bart Meyns receives research grants from CircuLite Inc., Saddlebrook, NJ, USA; Daniel Burkhoff is an employee of CircuLite Inc., Saddlebrook, NJ, USA.

Address for correspondence:

Steven Jacobs, MD

UZ Leuven

Campus Gasthuisberg

Herestraat 49

B - 3000 Leuven, Belgium

steven.jacobs@med.kuleuven.be

\section{REFERENCES}

1. Bui AL, Horwich TB, Fonarow GC. Epidemiology and risk profile of heart failure. Nat Rev Cardiol. 2011;8(1):30-41.

2. Curtis LH, Whellan DJ, Hammill BG, et al. Incidence and prevalence of heart failure in elderly persons, 1994-2003. Arch Intern Med. 2008;168(4):418-424.

3. Fang J, Mensah GA, Croft JB, Keenan NL. Heart failurerelated hospitalization in the U.S., 1979 to 2004. J Am Coll Cardiol. 2008;52(6):428-434.

4. McCullough PA, Philbin EF, Spertus JA, Kaatz S, Sandberg KR, Weaver WD; Resource Utilization Among Congestive
Heart Failure (REACH) Study. Confirmation of a heart failure epidemic: findings from the Resource Utilization Among Congestive Heart Failure (REACH) study. J Am Coll Cardiol. 2002;39(1):60-69.

5. Bleumink GS, Knetsch AM, Sturkenboom MC, et al. Quantifying the heart failure epidemic: prevalence, incidence rate, lifetime risk and prognosis of heart failure The Rotterdam Study. Eur Heart J. 2004;25(18):1614-1619.

6. Levy D, Kenchaiah S, Larson MG, et al. Long-term trends in the incidence of and survival with heart failure. N Engl J Med. 2002;347(18):1397-1402.

7. Anker SD, Sharma R. The syndrome of cardiac cachexia. Int J Cardiol. 2002;85(1):51-66. 
8. Ezekowitz J, McAlister FA, Humphries $\mathrm{KH}$, et al; APPROACH Investigators. The association among renal insufficiency, pharmacotherapy, and outcomes in 6,427 patients with heart failure and coronary artery disease. J Am Coll Cardiol. 2004;44(8):1587-1592.

9. Lang CC, Mancini DM. Non-cardiac comorbidities in chronic heart failure. Heart. 2007;93(6):665-671.

10. Hillege HL, Nitsch D, Pfeffer MA, et al; Candesartan in Heart Failure: Assessment of Reduction in Mortality and Morbidity (CHARM) Investigators. Renal function as a predictor of outcome in a broad spectrum of patients with heart failure. Circulation. 2006;113(5):671-678.

11. Kirklin JK, Naftel DC, Kormos RL, et al. Third INTERMACS Annual Report: the evolution of destination therapy in the United States. J Heart Lung Transplant. 2011;30(2):115-123.

12. Miller LW, Pagani FD, Russell SD, et al; HeartMate II Clinical Investigators. Use of a continuous-flow device in patients awaiting heart transplantation. N Engl J Med. 2007;357(9): 885-896.

13. Rose EA, Gelijns AC, Moskowitz AJ, et al; Randomized Evaluation of Mechanical Assistance for the Treatment of Congestive Heart Failure (REMATCH) Study Group. Long-term use of a left ventricular assist device for end-stage heart failure. N Engl J Med. 2001;345(20):1435-1443.

14. Kamdar F, Boyle A, Liao K, Colvin-adams M, Joyce L, John $R$. Effects of centrifugal, axial, and pulsatile left ventricular assist device support on end-organ function in heart failure patients. J Heart Lung Transplant. 2009;28(4):352-359.

15. Letsou GV, Myers TJ, Gregoric ID, et al. Continuous axialflow left ventricular assist device (Jarvik 2000) maintains kidney and liver perfusion for up to 6 months. Ann Thorac Surg. 2003;76(4):1167-1170.

16. Sandner SE, Zimpfer D, Zrunek P, et al. Renal function after implantation of continuous versus pulsatile flow left ventricular assist devices. J Heart Lung Transplant. 2008;27(5):469-473.
17. Radovancevic B, Vrtovec B, de Kort E, Radovancevic R, Gregoric ID, Frazier OH. End-organ function in patients on long-term circulatory support with continuous- or pulsatileflow assist devices. J Heart Lung Transplant. 2007;26(8): 815-818.

18. Meyns BP, Simon A, Klotz S, et al. Clinical benefits of partial circulatory support in New York Heart Association Class IIIB and Early Class IV patients. Eur J Cardiothorac Surg. 2011;39(5):693-698.

19. Tsukamoto Y. [Principles and methodology of K/DOQI clinical guidelines]. Clin Calcium. 2004;14(5):689-692.

20. Levey AS, Eckardt KU, Tsukamoto Y, et al. Definition and classification of chronic kidney disease: a position statement from Kidney Disease: Improving Global Outcomes (KDIGO). Kidney Int. 2005;67(6):2089-2100.

21. Slaughter MS, Rogers JG, Milano CA, et al; HeartMate II Investigators. Advanced heart failure treated with continuous-flow left ventricular assist device. N Engl J Med. 2009; 361(23):2241-2251.

22. Hasin T, Topilsky Y, Schirger JA, et al. Changes in renal function after implantation of continuous-flow left ventricular assist devices. J Am Coll Cardiol. 2012;59(1):26-36.

23. Meyns B, Klotz S, Simon A, et al. Proof of concept: hemodynamic response to long-term partial ventricular support with the synergy pocket micro-pump. J Am Coll Cardiol. 2009; 54(1):79-86.

24. Ronco C, Haapio M, House AA, Anavekar N, Bellomo R. Cardiorenal syndrome. J Am Coll Cardiol. 2008;52(19): 1527-1539.

25. Liu PP. Cardiorenal syndrome in heart failure: a cardiologist's perspective. Can J Cardiol 2008;24(Suppl B):25B29B.

26. Nohria A, Hasselblad V, Stebbins A, et al. Cardiorenal interactions: insights from the ESCAPE trial. J Am Coll Cardiol. 2008;51(13):1268-1274. 